\title{
Enhanced Response of Human Circulating Erythroid Progenitor Cells to hGH and to IGF-I in Children with Insufficient Growth Hormone Secretion
}

\author{
YIGAL BARAK, ZVI ZADIK, YOCHEVED KAROV, AND TALIA HAHN \\ Institute for Pediatric Research, Kaplan Hospital, Rehovot, Israel
}

\begin{abstract}
The response of hematopoietic progenitors to the growth promoting effects of hGH and IGF-I has been documented. In this study, the effects of recombinant hGH and IGF-I on the growth of circulating erythroid burst forming cells (BFU-E) from growth-IGF-I retarded children with insufficient growth hormone secretion (IGHS) were evaluated and compared with values obtained from either children with short stature and normal growth hormone levels (SNGH) or normal donors. Both recombinant $\mathbf{h G H}$ and IGF-I had significantly greater stimulatory effects on the growth of BFU-E from the IGHS compared with the SNGH and with the normally growing children. At its optimal concentration of $200 \mu \mathrm{g} / \mathrm{L}$, recombinant hGH had a stimulatory effect on the growth of BFU-E from 11 IGHS children yielding a mean $\pm \mathrm{SD}$ value of $2.0 \pm 0.3-$ fold above the unstimulated controls compared with 1.45 \pm 0.16 -fold and $1.36 \pm 0.04$-fold stimulation of BFU-E from six SNGH and five normal donors, respectively. Similarly, IGF-I, at its optimal concentration of 0.065 $\mathrm{nmol} / \mathrm{L}(0.5 \mathrm{ng} / \mathrm{mL})$, stimulated IGHS-derived BFU-E growth $1.67 \pm 0.25$-fold above unstimulated controls, compared with $1.28 \pm 0.17$-fold and $1.3 \pm 0.1$-fold stimulation of BFU-E from SNGH and from normal donors, respectively. The hGH- and IGF-I-induced stimulatory effects could be neutralized by their respective specific MAb. This significantly increased reactivity of erythroid progenitors from growth-retarded IGHS children to the erythropoietic effects of hGH and IGF-I may be the result of increased availability of cell surface receptors to these hematopoietic "synergistic" factors, secondary to their ambient decreased circulating concentrations in vivo. In vitro studies of peripheral blood BFU-E responsiveness to hGH and to IGFI may be useful in implicating these peptides in growth retardation and possibly in predicting in vivo response to them. (Pediatr Res 32: 282-285, 1992)
\end{abstract}

\section{Abbreviations}

rEpo, recombinant erythropoietin

GH, growth hormone

BFU-E burst forming units-erythroid

IGHS, insufficient growth hormone secretion

SNGH, short stature with normal growth hormone secretion

$\mathrm{PB}$, peripheral blood

rhGH, recombinant human growth hormone

Received November 28, 1991; accepted April 7, 1992.

Correspondence: Yigal Barak, M.D., Department of Pediatrics A, Kaplan Hospital, Rehovot, 76100, Israel.
hGH and IGF-I are polypeptides that regulate proliferation and metabolic processes in a variety of mammalian cell types (1). Considerable evidence exists indicating an effect of these peptides in normal human erythropoiesis. Both hGH and IGF-I induce potentiation of colony formation by erythroid (BFU-E) as well as myeloid progenitor cells from normal human donors (2-5). IGF-I, which is presumed to mediate the effect of GH in various tissues, probably is the mediator of $\mathrm{GH}$ in erythropoiesis (4), although some reports suggest a direct effect of hGH on BFU-E $(1,2,6)$. Studies on leukemic cell lines as well as on freshly obtained marrow cells from children with acute leukemia also indicate that $\mathrm{hGH}$ and IGF-I may enhance in vitro human leukemic cell proliferation (7).

Growth retardation in children often is associated with low circulating $\mathrm{GH}$. No data as to the in vitro erythroid response to either hGH or IGF-I are available in those children. However, in growth-retarded children with Laron dwarfism, a disorder characterized by high levels of circulating $\mathrm{GH}$, subnormal levels of circulating IGF-I, and unresponsiveness to $\mathrm{hGH}$, peripheral BFU-E were found to be unresponsive to in vitro treatment with $\mathrm{hGH}(6)$. The present study was therefore undertaken to examine the response of erythroid progenitors from donors with insufficient $\mathrm{GH}$ secretion to the erythropoietic effects of hGH and IGF$\mathrm{I}$ in comparison with the response of progenitors from donors with normal GH levels.

\section{MATERIALS AND METHODS}

Patients. Seventeen patients, eight boys and nine girls, between the ages of 6.5 and 14.5 y were studied. All patients had growth retardation with growth velocity below -2 SD for their chronologic age and gender. They were divided into two groups: Eleven (six boys and five girls) were diagnosed as having IGHS, based on their subnormal spontaneous 24-h GH serum integrated concentration levels $(2.37 \pm 0.71 \mu \mathrm{g} / \mathrm{L})(8)$. Their $\mathrm{GH}$ responses to provocative tests with insulin, arginine, and clonidine $(9,10)$ were, however, within normal range $(16.03 \pm 9.2 \mu \mathrm{g} / \mathrm{L})$. The second group of six children (two boys and four girls), whose $\mathrm{GH}$ serum integrated concentration and GH responses to provocative tests were normal $(4.88 \pm 1.48$ and $29.73 \pm 13.2 \mu \mathrm{g} / \mathrm{L}$, respectively), were defined as children with short stature and normal $\mathrm{GH}$, and together with five healthy, age-matched children of normal stature, served as a control group. Hb levels, reticulocyte counts, red blood cell counts, and mean corpuscular volume values were within normal range in both the study and the control groups. Participation of all children studied was contingent on obtaining parental informed consent, conforming with institutional standards and approved protocols for research involving human subjects.

Assay for BFU-E. Heparinized PB samples were layered on Ficoll-Hypaque gradients and centrifuged to obtain the mononuclear cell fraction. Circulating BFU-E were measured by a 
modification of the assay of Dukes et al. (11). Mononuclear PB cells were plated at $5 \times 10^{5}$ in $1 \mathrm{ml}$ of Iscove's modified Dulbecco's medium containing 30\% FCS, $0.8 \%$ methylcellulose, and a stimulating dose of 1 unit of rEpo (Eprex, Cilag, Switzerland). The GH and IGF-I levels in FCS were $<0.1 \mu \mathrm{g} / \mathrm{L}$ and $<3$ $\mathrm{nmol} / \mathrm{L}$, respectively. Cultures were incubated in a humidified atmosphere of $5 \% \mathrm{CO}_{2}$ at $37^{\circ} \mathrm{C}$, and colonies were scored in duplicate cultures after $10 \mathrm{~d}$. Before plating, cells were pulsed for $48 \mathrm{~h}$ at $37^{\circ} \mathrm{C}$ in $5 \% \mathrm{CO}_{2}$, in liquid medium with rhGH (Biotechnology, Rehovot, Israel) or IGF-I (Incstar, Stillwater, MN) at the indicated concentrations in the presence or absence of their respective antibodies [i.e. anti-hGH (Oris Industries, Yvepte, France) or anti-IGF-I (Incstar)]. Anti-hGH and IGF-I were added to the incubated cells at $1: 200$ and $1: 1000$ dilutions, respectively, $2 \mathrm{~h}$ before the addition of hGH or IGF-I.

Statistical analysis. Data are presented as the mean \pm SD. The significance of difference between mean values was calculated using the $t$ test.

\section{RESULTS}

Enhancement of BFU-E by rhGH, in rEpo-stimulated cultures, could be detected at a hormone concentration of $50 \mu \mathrm{g} / \mathrm{L}$ and was maximal at $200 \mu \mathrm{g} / \mathrm{L}$ (Fig. 1). It should be noted that BFU-E colony numbers in the control cultures (i.e. no hormone added) were $39 \pm 12,29 \pm 7$, and $30 \pm 5$ per $5 \cdot 10^{5}$ cells in the IGHS, SNGH, and normal donors groups, respectively, and were not significantly different $(p>0.11)$. Potentiation of BFU-E colony formation in cell cultures from the IGHS children, using $200 \mu \mathrm{g} / \mathrm{L}$ rhGH $(2.0 \pm 0.3$-fold of control BFU-E; $p<0.01)$ was significantly greater $(p<0.002)$ than the increase observed in cell cultures from growth-retarded children with normal $\mathrm{GH}$ ( $1.45 \pm 0.16$-fold of control) and was also significantly greater ( $p$ $<0.001)$ than the increase observed in cultures from normal donors (1.36 \pm 0.04 -fold of control BFU-E). Furthermore, the frequency of the observed $\mathrm{GH}$-induced increase in BFU-E growth of $>1.5$-fold was $91 \%$ ( 10 of 11 ) of the IGHS children, $33 \%$ (two of six) of the SNGH group, and none (zero of five) of the normal donors.

IGF-I-induced enhancement of BFU-E was detected at a concentration of $0.032 \mathrm{nmol} / \mathrm{L}(0.25 \mathrm{ng} / \mathrm{mL})$ and was maximal at $0.065 \mathrm{nmol} / \mathrm{L}(0.5 \mathrm{ng} / \mathrm{mL})$ (Fig. 2). Potentiation of BFU-E colony formation in cell cultures from the IGHS children, using $0.5 \mathrm{ng} / \mathrm{mL}$ recombinant IGF-I ( $1.67 \pm 0.25$-fold of control BFU$\mathrm{E} ; p<0.007)$, was significantly greater $(p<0.006)$ than the

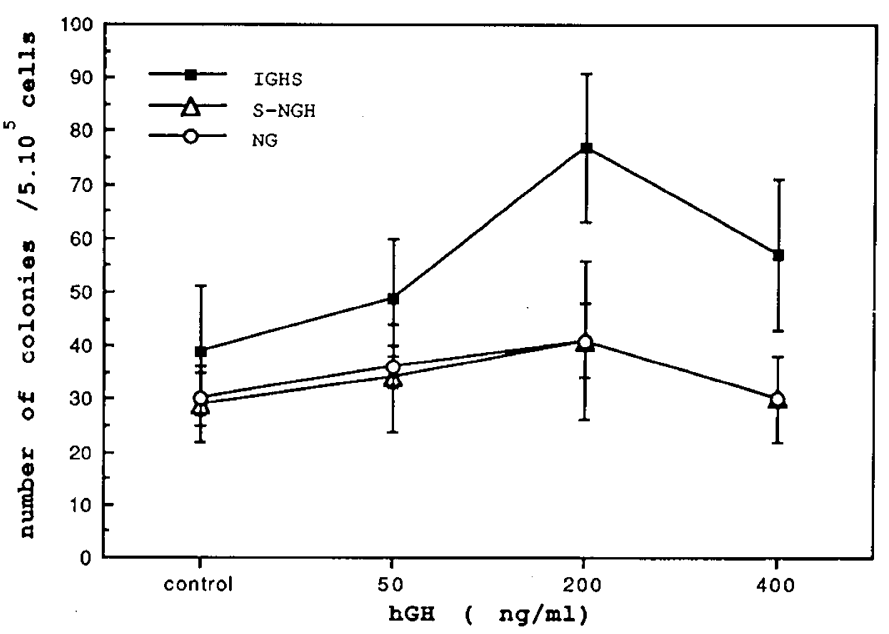

Fig. 1. Effect of hGH on development of BFU-E cultured in vitro from the peripheral blood of 11 patients with IGHS, six children with short stature and normal GH $S$ - NGH, and five normal growing children $N G$. Cultures were stimulated with 1 unit of rEpo. Results represent the mean $\pm \mathrm{SD}$ of all patients of each group, performed in duplicate. Conversion to SI units: hGH $(\mu \mathrm{g} / \mathrm{L})=(\mathrm{ng} / \mathrm{mL})$.

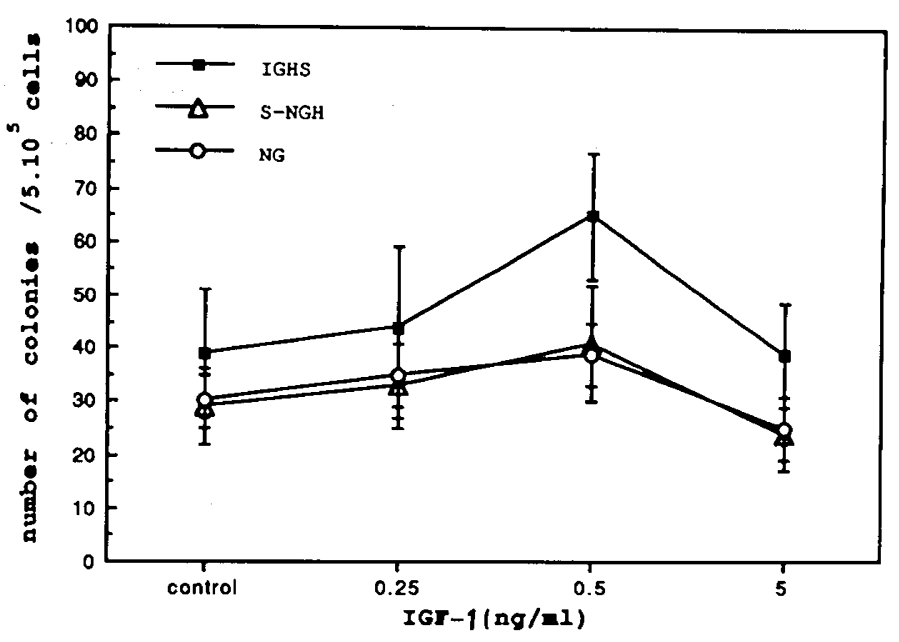

Fig. 2. Effect of IGF-I on development of BFU-E cultured in vitro from the $\mathrm{PB}$ of the studied patients. Conversion to SI units: IGF-I (nmol/ $\mathrm{L})=(\mathrm{ng} / \mathrm{mL}) \times 0.1307$. Abbreviations as in Figure 1 .

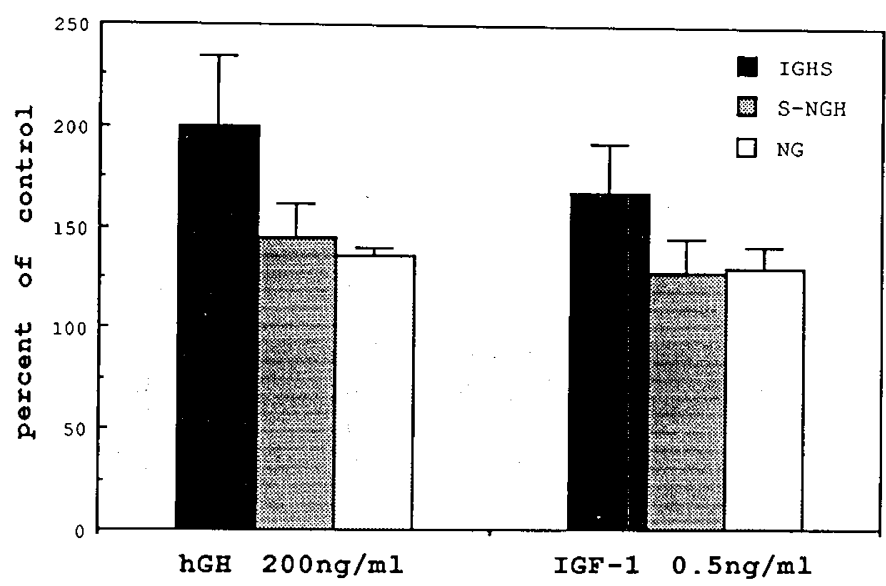

Fig. 3. Effect of hGH and IGF-I at their optimal concentrations on the growth of BFU-E from the PB of the studied patients, expressed as $\%$ of control (no hormone added). Abbreviations as in Figure 1.

increase observed in cell cultures from SNGH children $(1.28 \pm$ 0.17 -fold of control) and was also significantly greater $(p<$ 0.009 ) than the increase observed in cultures from normal donors (1.3 \pm 0.1 -fold of control) (Fig. 3). The frequency of the observed IGF-I-induced increase in BFU-E growth of $>1.5$-fold was $67 \%$ (six of nine) of the IGHS children, 17\% (one of six) of the SNGH children, and none (zero of five) of the normal control group.

The specificity of the described hormone-induced growthpotentiating effects was studied in the PB cultures of three IGHS patients and was demonstrated by the complete neutralization of the hGH-induced effect using an anti-hGH antibody (at a dilution of 1:200) and of the IGF-I-induced effect using an antiIGF-I antibody (at a dilution of 1:1000) (Fig. 4).

\section{DISCUSSION}

Previous studies have demonstrated that hGH and IGF-I enhance in vitro proliferation of erythroid precursors $(2,4-6)$, and recent reports also have shown that both $\mathrm{hGH}$ and IGF-I enhance the in vitro growth of human bone marrow derived granulomonocytic colonies (3) and of leukemic blast colonies (7). Growth-retarded children with isolated GH deficiency are not regularly presented with significant anemia, although this finding has been postulated by at least one report (5). It has been long established, however, that hypophysectomized animals are anemic and that patients with pituitary malfunction suffer from a similar condition $(12,13)$. The anemia and the impaired DNA 


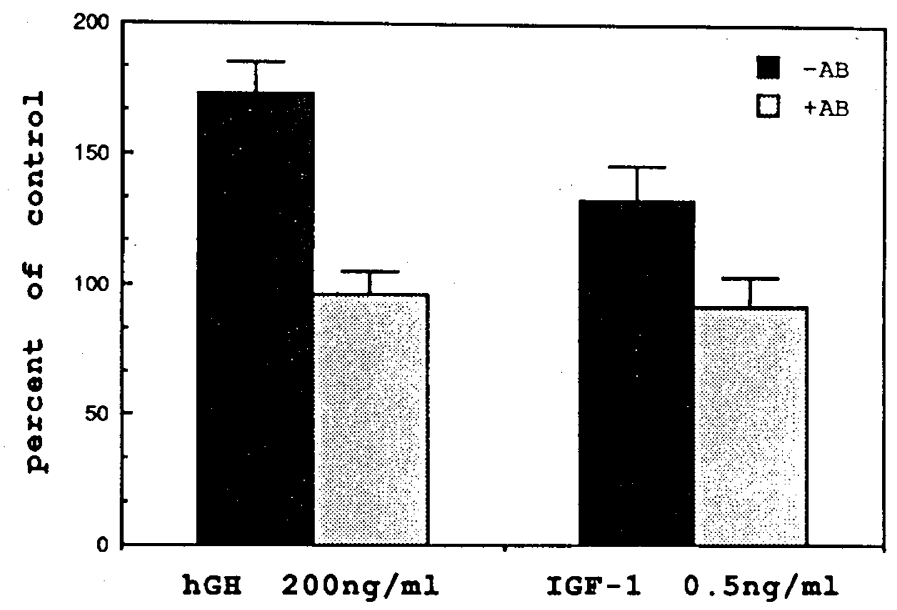

Fig. 4. Neutralization of hGH and IGF-I-induced enhancement of PB BFU-E growth by anti-hGH and IGF-I antibodies $(A B)$. Each bar represents the mean \pm SD of BFU-E from the peripheral blood of three IGHS patients expressed as \% of control. AntihGH and IGF-I AB were added at 1:200 and 1:1000 dilutions, respectively.

and RNA synthesis in the bone marrow of hypophysectomized rats could be restored by GH (14), whereas treatment of prepubertal hypopituitary dwarfs with $\mathrm{hGH}$ in doses sufficient to induce linear growth induced increased hematopoiesis (13). In contrast, hGH failed to enhance erythropoiesis in acromegalic patients (15).

This study compares the response to hGH and to IGF-I of erythropoietic progenitor cells from 11 patients with insufficient $\mathrm{GH}$ secretion [a short-stature disorder characterized by a subnormal spontaneous $\mathrm{GH}$ secretion but a normal response to provocative tests, previously termed "neurosecretory dysfunction" (16)] with the response of cells from six growth-retarded patients with normal GH levels and five normally growing children. Focusing on growth-retarded children with IGHS as the study group seems to be appropriate because several reports have claimed that children with IGHS may represent a subset of growth-retarded patients with subnormal GH levels who could benefit from hGH therapy $(8,16,17)$. Indeed, treatment of IGHS children for $2 \mathrm{y}$ with hGH elicits a marked growth response similar to that noted in patients with a subnormal $\mathrm{GH}$ response to provocative tests (18). BFU-E from the IGHS children were significantly more responsive to the erythropoietic potentiating effects of both hGH and IGF-I than to BFU-E from the growthretarded patients with normal $\mathrm{GH}$ levels or from normal donors.

The mechanism whereby hGH, alone or mediated by IGF-I, enhances the in vitro growth of human erythroid progenitors is not clear. Recent studies have shown that murine Friend erythroleukemia cells were specifically stimulated by GH (19) and, furthermore, that hGH acted as a potent direct stimulator of the human erythroleukemia cell line K562 (20). Indeed, membrane receptors for IGF-I have been detected in human erythrocytes (21).

Recently, attention has been directed toward several growth factors that do not stimulate hematopoietic colony formation directly but enhance the response of hematopoietic stem cells to specific proliferative and differentiative signals of terminal growth factors. GH and IGF-I may be classified as an example of those "synergistic hematopoietic growth factors" (22). It has been suggested that exposure to these synergistic hormones may be required for the initiation of DNA synthesis and hematopoietic cell division. Although the mechanism of this synergism is not clear, an attractive hypothesis, supported by some experimental evidence (23), suggests the induction of enhanced receptor expression in primitive stem cells, more of which then become responsive to specific inducers of terminal differentiation. The cause for the significantly greater response of erythroid progeni- tors from patients with insufficient $\mathrm{GH}$ secretion to the synergistic hematopoietic effect of both GH and IGF-I remains unresolved. Because clinically a correlation exists between the initial GH levels and the achieved linear growth in growth-retarded patients under hGH therapy (18), by analogy the increase in responsiveness of their hematopoietic cells to GH and to IGF-I may be the result of an increased availability of cell surface receptors to these peptides, secondary to their decreased circulating concentrations in vivo. In disorders associated with increased circulating $\mathrm{GH}$ levels such as acromegaly, no erythropoietic effect of $\mathrm{GH}$ could be detected (15). The performance of receptorbinding studies would have undoubtedly elucidated the mechanisms involved in the effects of "synergistic" factors in the enhancement of in vitro erythropoiesis in IGHS patients. Unfortunately, these were not performed in the present study because it is extremely difficult to isolate human PB hematopoietic progenitors in sufficient quantity for such studies. Changes in the BFU-E response to hGH and IGF-I in these patients, after $\mathrm{hGH}$ therapy, is under investigation.

These findings indicate that in vitro studies of erythroid progenitor responsiveness to GH and to IGF-I may be useful in implicating those peptides in growth retardation, as well as in predicting in vivo responses to them. In addition, the findings suggest a possible hematopoietic synergistic effect of GH or IGFI in children with other disorders such as end-stage renal disease, a condition characterized by erythropoietin responsive anemia (24), in which growth retardation currently is being treated by $\mathrm{hGH}(25)$. The potential synergism between the hormones hGH and IGF-I and the hematopoietic growth factor rEpo on erythropoietic cell growth in these children is under investigation.

\section{REFERENCES}

1. Golde DW, Herschman HR, Lusis AJ 1980 Growth factors. Ann Intern Med 92:650-654

2. Golde DW, Bersch N, Li CH 1977 Growth hormone: species-specific stimulation of erythropoiesis in vitro. Science 196:1112-1113

3. Merchav S, Tatarsky I, Hochberg Z 1988 Enhancement of human granulopoiesis in vitro by biosynthetic insulin-like growth factor 1 /somatomedin C and human growth hormone. J Clin Invest 81:791-797

4. Merchav S, Tatarsky I, Hochberg Z 1988 Enhancement of erythropoiesis in vitro by human growth hormone is mediated by insulin-like growth factor 1. Br J Hematol 70:267-271

5. Claustres M, Chatelain P, Sultan C 1987 Insulin-like growth factor 1 stimulates human erythroid colony formation in vitro. J Clin Endocrinol Metab 65:7882

6. Golde DW, Bersch N, Kaplan SA, Rimoin DL, Li CH 1980 Peripheral unresponsiveness to human growth hormone in Laron dwarfism. N Engl J Med 303:1156-1159

7. Estrov Z, Meir R, Barak Y, Zaizov R, Zadik Z 1991 Human growth hormone and insulin-like growth factor-1 enhance lymphoblastic and myelogenous leukemia cell proliferation in vitro. J Clin Oncol 9:303-306

8. Zadik Z, Chalew SA, Kowarski AA 1985 Do short children secrete insufficient growth hormone? Pediatrics 76:355-360

9. Raiti S, Davis WT, Blizzard RM 1967 A comparison of the effects of insulin hypoglycemia and arginine infusion on release of human growth hormone. Lancet 2:1182-1183

10. Lanes R, Hurtado E 1982 Oral clonidine: an effective growth hormone releasing agents in prepubertal subjects. J Pediatr 100:710-714

11. Dukes PP, Ma A, Clemons GK, Meitas D 1985 Measurement of erythroid burst promoting activity by a specific cell culture assay. Exp Hematol 13:5960

12. Crafts RC, Meineke HA 1959 The anemia of hypophysectomized animals. Ann NY Acad Sci 77:501-517

13. Jepson JH, McGarry EE 1972 Hemopoiesis in pituitary dwarfs treated with human growth hormone and testosterone. Blood 39:238-248

14. Nagy E, Berczi I 1989 Pituitary dependence of bone marrow function. Br J Haematol 71:457-462

15. Jepson $\mathrm{J} 1968$ Agents influence the production and action of erythropoietin in man. J R Coll Phys 2:238-245

16. Spiliotis BE, August GP, Hung W, Sonis W, Mendelson W, Bercu BB 1984 Growth hormone neurosecretory dysfunction: a treatable cause for short stature. JAMA 251:2223-2230

17. Chalew SA, Raiti S, Armour KM, Kowarski AA 1977 Therapy in short children with subnormal integrated concentrations of growth hormone. Am J Dis Child 141:1195-1198

18. Zadik Z, Landau H, Rosenberg M, Limoni Y, Lieberman E 1992 Who will benefit from growth hormone therapy? Growth hormone therapy in short children. J Pediatr Endocrinol (in press) 
19. Golde DW, Bersch N, Li CH 1978 Growth hormone modulation of murine erythroleukemia cell growth in vitro. Proc Natl Acad Sci USA 75:3437-3439

20. Gauwerky C, Golde DW, Li CH 1980 Growth hormone polypeptides stimulate proliferation of K562 human erythroleukemia cells. J Clin Endocrinol Metab $51: 1208-1210$

21. Polychronakos C, Guyda HJ, Posner BI 1983 Receptors for the insulin like growth factors on human erythrocytes. J Clin Endocrinol Metab 57:436440

22. Quesenberry PJ 1986 Synergistic hematopoietic growth factors. Int J Cell Cloning 4:3-15
23. Neckers LM, Cossman J 1983 Transferrin receptor induction in mitogen stimulated human $T$ lymphocytes is required for DNA synthesis and cell division, and is regulated by interleukin 2. Proc Natl Acad Sci USA 80:34933498

24. Sinai-Traiman L, Salusky IB, Fine R 1989 Use of subcutaneous recombinant human erythropoietin in children undergoing continuous cycling peritoneal dialysis. J Pediatr 114:550-554

25. Lippe B, Fine R, Koch VH, Sherman BM 1988 Accelerated growth following treatment of children with chronic renal failure with recombinant human growth hormone (somatrem): a preliminary report. Acta Paediatr Scand [Suppl] 343:127-131

\section{Erratum}

In the article "Oxygen-Related Prostaglandin Synthesis in Ductus Arteriosus and Other Vascular Cells" by Marlene Rabinovitch et al. (Pediatr Res 26:330-335, 1989), the labels on the left axes of Figure 3 were transposed. The corrected figure is shown below. We regret this error.

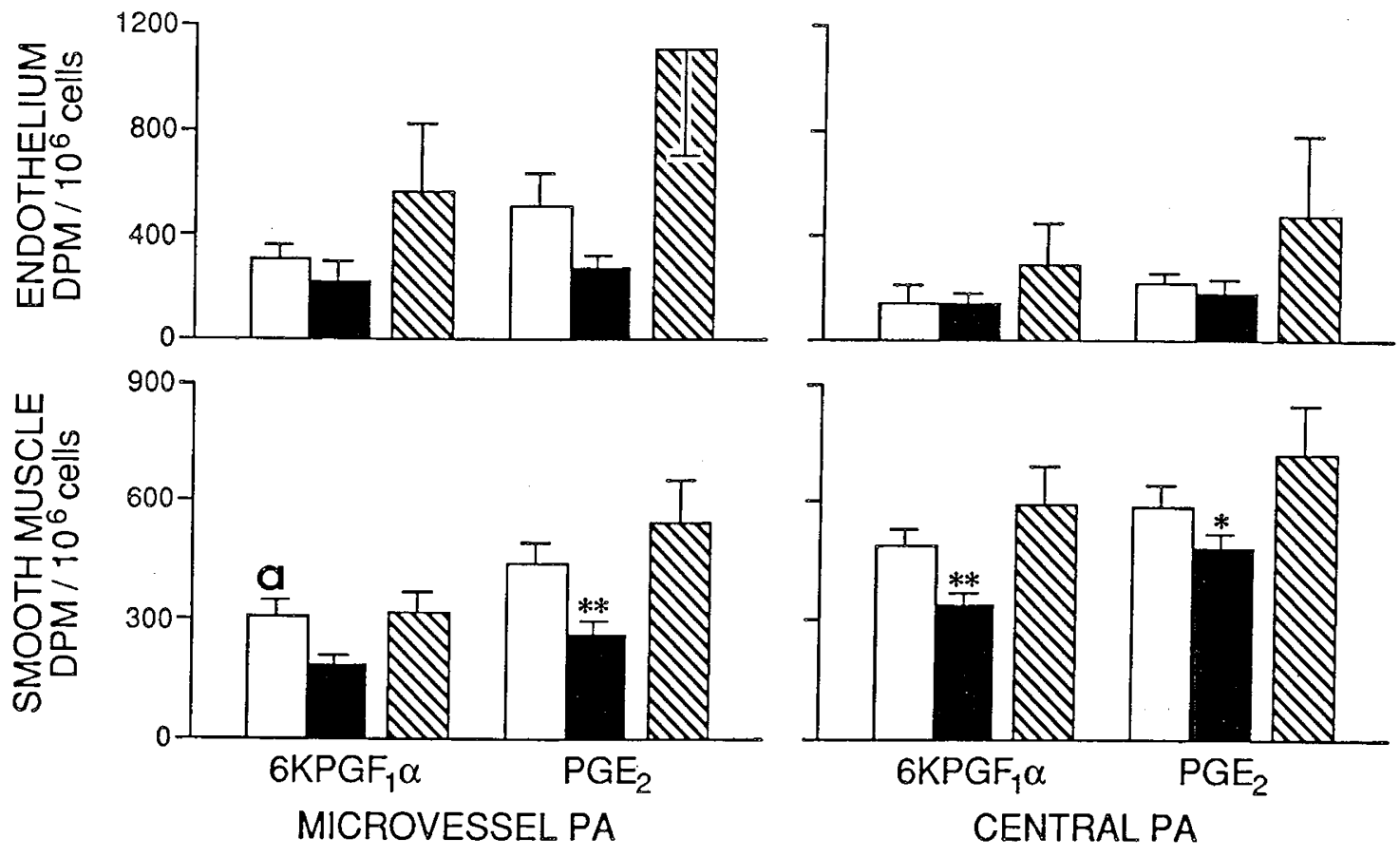

